
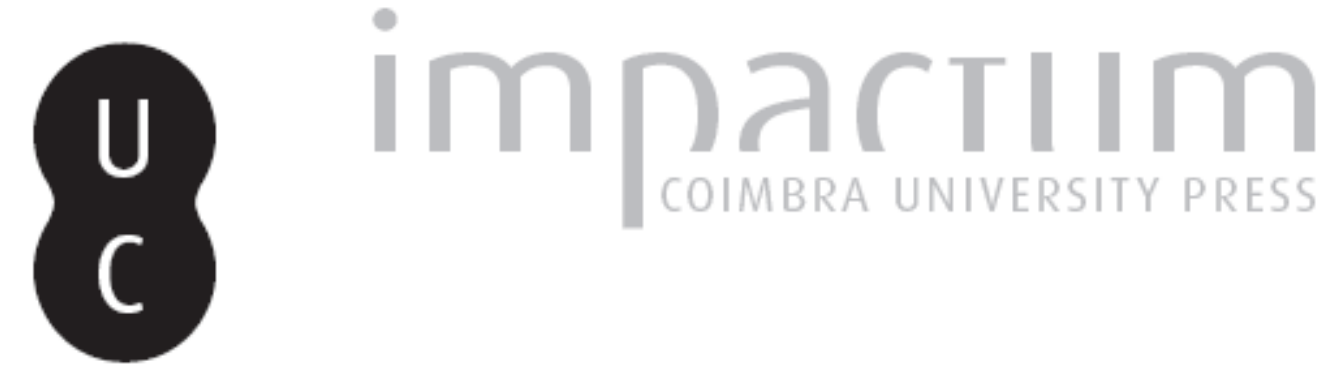

\title{
La Revolución Francesa en la prensa española de la epoca: el Mercurio Historico y Politico: (de Termidor a Basilea)
}

\author{
Autor(es): $\quad$ Saiz, M. ${ }^{\text {a }}$ Dolores
}

Publicado por: Imprensa da Universidade de Coimbra

URL persistente:

URI:http://hdl.handle.net/10316.2/43789

DOI:

DOI:https://doi.org/10.14195/2183-8925_10_30

Accessed : $\quad$ 26-Apr-2023 10:20:49

A navegação consulta e descarregamento dos títulos inseridos nas Bibliotecas Digitais UC Digitalis, UC Pombalina e UC Impactum, pressupõem a aceitação plena e sem reservas dos Termos e Condições de Uso destas Bibliotecas Digitais, disponíveis em https://digitalis.uc.pt/pt-pt/termos.

Conforme exposto nos referidos Termos e Condições de Uso, o descarregamento de títulos de acesso restrito requer uma licença válida de autorização devendo o utilizador aceder ao(s) documento(s) a partir de um endereço de IP da instituição detentora da supramencionada licença.

Ao utilizador é apenas permitido o descarregamento para uso pessoal, pelo que o emprego do(s) título(s) descarregado(s) para outro fim, designadamente comercial, carece de autorização do respetivo autor ou editor da obra.

Na medida em que todas as obras da UC Digitalis se encontram protegidas pelo Código do Direito de Autor e Direitos Conexos e demais legislação aplicável, toda a cópia, parcial ou total, deste documento, nos casos em que é legalmente admitida, deverá conter ou fazer-se acompanhar por este aviso.

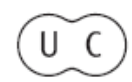


REVISTA DE HISTORIA DAS IDEIAS IO
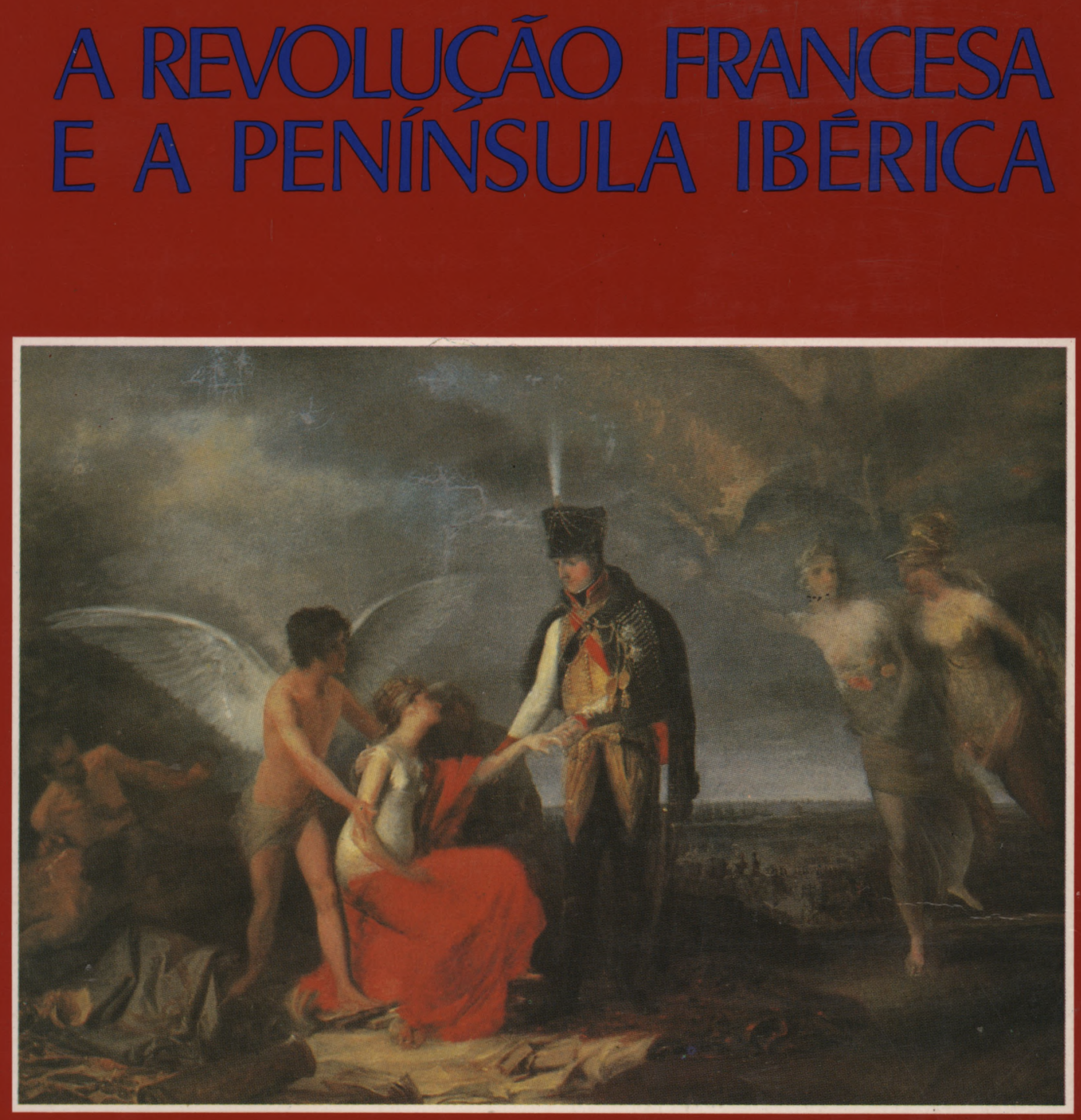

INSTITUTO DE HISTÖRIA E TEORIA DAS IDEIAS FACULDADE DE LETRAS 


\title{
LA REVOLUCIÓN FRANCESA EN LA PRENSA ESPAÑOLA DE LA EPOCA. EL MERCURIO HISTORICO Y POLITICO:
}

\author{
(DE TERMIDOR A BASILEA)
}

1. Hacia una normalización de las relaciones entre España y Francia

En su Historia del reinado de Carlos IV, Andrés Muriel manifestaba su admiración par el valor extraordinario de los soldados franceses en su lucha contra los enemigos de la Revolución:

"General fue el ardor bélico, universal el entusiasmoescribe en su crónica - Todos los hombres aptos para la guerra corrieron a tomar las armas sin distinción de estados ni condiciones. Llenas estaban las plazas públicas donde se hacían los alistamientos, y los caminos que llevaban a la frontera estuvieron también cubiertos muy en breve de voluntarios que buscaban ansiosos la ocasión de pelear contra los enemigos. Dejando las dulzuras y placeres de la vida doméstica, emprenden gustosos los trabajos de la guerra....» (1).

Los rumores sobre los graves peligros que amenazaban a la patria recorrieron la joven República francesa en el verano de 1793 actuando como elemento catalizador del sentimiento nacional frente a las presiones extranjeras.

* Universidad Complutense de Madrid.

** Esta ponencia constituye la segunda parte de la presentada en el Coloquio internacional cebrado en Madrid bajo el título: «La Revolución Francesa en la Prensa española de la época: el "Mercurio histórico y político" (1789-1793) y abarca el periodo comprendido entre el 27-VII-94-22-VII-95.

(1) Andrés Muriel, Historia de Carlos IV, Madrid, Atlas, 1959, T. CXIV y CXV, I., p. 128. 
Los éxitos militares de 1794 en Bélgica, el Palatinado, Tréveris, y en norte de España, contra los paises que integraban la primera coalición, tuvieron el doble efecto de alentar en fervor revolucionario y elevar la moral maltrecha de un ejército sometido a muchas vejaciones en los momentos iniciales de la guerra. Para los españoles, sin embargo, las campañas de ese año resultaron desastrosas, creando en el ejército una conciencia de derrota que parecía insuperable:

\begin{abstract}
«...el hambre y las enfermedades - escribía Godoy en sus Memorias - ejercitaban allí largamente la perseverancia española: desde fin de julio no tenía cada hombre sino la cuarta parte de una ración comenzada por los gusanos. Rematados ya los arbitrios de esta larga cuaresma de la Patria no quedó animal inmundo que no sirviese de regalo a aquellos dignos militares" (2).
\end{abstract}

En el verano de 1794 , la guerra, «querida y provocada.... por los que entonces gobernaban en la Francia, y que de parte de España fue una necesidad inevitable», pasaba por momentos especialmente críticos apesar del entusiasmo inicial que había presentado la lucha contra el francés como una cruzada en defensa de la religión y de la patria, apoyada en el fervor y en la generosidad popular: desde «los tesoros del Grande de Castilla hasta el pobre maravedí del mendigo». Pero en 1794 aquel entusiasmo se había disipado, cuando los franceses ocuparon las plazas de Figueras y San Sebastián, y, en 1795 las de Bilbao y Vitoria, acelerando las conversaciones de paz.

Sin embargo, la guerra, a pesar de la propaganda, no había sido aceptada por todas las fuerzas políticas; Godoy alude en sus Memorias a la reacción negativa de un sector de la clase política

"corto en número y recatado, mas no del todo sin influjo, que vió con pena la coalición contra la Francia, y que al voto nacional, tan pronunciado en favor de ella, lo graduó de un movimiento pasagero, que la influencia de las clases superiores, y la sugestión del clero habían causado en la muchedumbre ciega de las plebes» $\left({ }^{3}\right)$.

Un rechazo provocado por la influencia que sobre algunos políticos e intelectuales habían ejercido «las ideas nuevas, con que el siglo llenaba al mundo de esperanzas y temores».

(2) Manuel Godoy, Príncipe de la Paz, Memorias críticas y apologéticas para la historia del Reinado del Señor D. Carlos IV de Borbón, Madrid, Atlas, 1965, T. 1, p. 92.

(3) Manuel Godoy, Memorias..., I, p. 66. 
La llamada a los responsables de los ejércitos que operaban en el norte, en marzo del 94, proyectada para planificar nuevas campañas, iba a transformarse en un debate sobre el sentido de la guerra en el que Aranda apostó sin titubeos por la paz, defendiendo la neutralidad armada frente a una guerra que consideraba injusta, impolítica, «superior a nuestras fuerzas» y además, arriesgada para la monarquía; en opinión de Godoy, sin embargo, una guerra justa y salvadora contra un gobierno "perturbador, que predica la impiedad, el sacrilegio, el despojo, la destrucción y la ruina de cuanto existe».

Muy pronto, el proyecto de paz defendido por Aranda - causa importante de su caida -, iba a encontrar vía libre en los planes del Gobierno, cuando las dificultades planteadas dentro y fuera del país imponían una nueva orientación de la política española frente a Francia. Para Godoy, la paz estaba justificada en el caso de que «por resultado de una reacción dichosa, aparezcan (en el Gobierno francés) otras personas, otras leyes, otras máximas de política, otro sistema, en fin, que ofrezca garantía a las naciones y permita entenderse con la Francia» $\left.{ }^{4}\right)$.

El camino hacia la concordia parecía definitivamente abierto tras la "gran jornada de Termidor» en la que muchos miembros cualificados del Gobierno veían el fin de la tiranía revolucionaria. Francia desde una postura más templada deseaba la paz y la armonía con sus vecinos de Europa y, "se indignaba.... - según relatan las Memorias - de sufrir el desvío de los pueblos civilizados por los principios execrables con que la deshonraron sus tiranos»; la República antes rechazada aparecía ahora legitimada por la fuerza de las armas. La coalición perdía sentido en la medida en que desaparecían las causas que la habían impulsado.

La Diplomacia española supo aprovechar hábilmente la nueva coyuntura francesa en un contexto político interno enrarecido, en el que podía percibirse un cierto malestar, provocado por algunos rumores que hablaban de intentos sediciosos y de conspiración: «En Madrid - escribía Muriel en su crónica - no dejaba de haber cabezas ardientes que profesaban grande admiración por los novadores y creyesen hacedero plantear en España las mismas reformas que en Francia» $\left({ }^{5}\right)$. Entre los proyectos de conspiración tuvo especial resonancia el protagonizado por Picornell, personaje tozudo que llamaba a la revolución desde papeles como el «Manifiesto» y la «Instruc-

(4) Manuel Godoy, Memorias...., 1, p. 100.

(5) Andrés Muriel, Historia de Carlos IV. T. I, p. 180. 
Revista de História das Ideias

ción», una tentativa verosimil abocada inexorablemente al fracaso $\left({ }^{6}\right)$.

\section{El «Mercurio histórico y político» en los años 90}

El Mercurio histórico y político incorporado a la Corona por una Real Orden de 24 de enero de 1756, seguía reuniendo las mismas características que en el periodo precedente en cuanto a periodicidad, tirada y formato, cumpliendo su objetivo inicial de procurar a los lectores información puntual sobre cuestiones de política internacional, «las novedades de Europa» como había dicho en su presentación. Mantenía su precio de 2 reales, había rebajado algo su tirada y seguía imprimiéndose en la Imprenta Real. Dirigido desde 1773 hasta 1779 por José Clavijo y Fajardo modernizó su contenido, mostrando ahora interés por algunos de los temas más conflictivos del momento: las noticias sobre las doctrinas y prácticas de Ricci y del gran duque Leopoldo de Toscana, de clara inspiración jansenista, fueron publicadas e incluso defendidas desde las páginas del Mercurio histórico en la medida en que contribuían, en opinión del cronista, a la pureza y autenticidad del Evangelio $\left({ }^{7}\right)$. El Mercurio, que, como dijimos, había alcanzado gran éxito en torno a los años 80 , había renovado su título, Mercurio de España desde 1784, incluyendo importantes reportajes; para Guinard, el periódico oficial era «source d'informations excepcionnellement riche, est le plus moderne des jornaux espagnols» $\left({ }^{8}\right)$.

${ }_{\left({ }^{6}\right)}$ Sobre la conspiración de Picornell: A. Elorza, "Conspiración de Picornell (1795)». en Pan y Toros y otros papelies sediciosos de fines del siglo XVIII, Madrid, Ayuso, 1971, pp. 75-87 y del mismo autor La ideología liberal en la Ilustración española, Madrid, Tecnos, 1970, en concreto Apéndice II, pp. 304-309.

(7) Sobre el Mercurio, cfr. P. J. Guinard, La Presse espagnole de 1737 a 1791. Formation et signification d'un genre, París, Centre de Recherches Hispaniques, 1973. E. Cotarelo y Mori, Iriarte y su época, Madrid, 1897. J. Trenas, "Mercurio histórico y político", Gaceta de la Prensa Española, 1942, noviembre, num. 6, pp. 341-368. L.M. Enciso Recio, La Gaceta de Madrid y el Mercurio histórico y político, 1756-1781, Universidad de Valladolid, 1959. Francisco Aguilar Piñal, La prensa española en el siglo XVIII. Diarios. Revistas y Pronósticos, Cuadernos Bibliográficos, Madrid, C.S.I.C., 1978. Sobre el jansenismo en la prensa española: M.a Giovanna Tomsich, El jansenismo en España, Estudio sobre ideas religiosas en la segunda mitad del siglo XVIII, Madrid, Siglo XXI, 1972.

(8) Guinard, La Presse..., p. 223. 
En los años 90 el Mercurio había iniciado ya una fase de decadencia provocada por la aparición de periódicos nuevos ágiles y modernos, como el Memorial Literaria Como publicación oficial seguía vinculado a la Corona y dependía directamente de la Secretaría de Estado, disfrutando de abundantes recursos económicos y de una buena distribución $\left(^{9}\right)$. Dedicado sobre todo a la información extranjera, sus largas y detalladas crónicas sobre los principales paises europeos reflejan fielmente los intereses políticos del Gobierno. En este sentido, el nuevo espíritu que inspira las «Noticias de Francia» desde Termidor, muestra un proceso lento y firme al mismo tiempo, hacia la conciliación con el país vecino, acorde con los nuevos objetivos de la política exterior española.

La lectura de las crónicas del Mercurio sobre los acontecimientos franceses en estas fechas permite señalar dos etapas claramente diferenciadas en las que la reacción termidoriana marcó un hito informativo, lo mismo que ocurrió en los primeros años de la Revolución con la ejecución de Luís XVI; antes del 27 de julio del 94, las «Noticias» manifiestan una gran hostilidad hacia los acontecimientos y la política del país vecino, una condena radical de todo el proceso revolucionario - en pleno periodo del Terror - de la represión, el crimen, la corrupción y la mi-

(9) Sobre Prensa y censura y Prensa y Revolución francesa: L. Domergue, Tres calas en la censura diecıchesca (C'adalso, Rousseau, prensa periódica), Institut d'Etudes Hispaniques et Hispanoamericaines, Universidad de Toulouse, Le Mirail, 1981; C'ensure et lumieres dans l'Espagne die C'harles III, París, C.R.H., 1982 y Le livre en Espagne au temps de la Revolution Française, Presse Universitaires de Lyon, 1984; M. Defourneaux, Inquisición y censura de libros en la España del siglo XVIII, Madrid, Taurus, 1973; "Jansenisme et regalisme dans l'Espagne du XVIII siecle», Caravelle, Toulouse, num. 11, 1968, y Pablo de Olavide ou l'afrancesado (1725-1803), P.U.F., Paris, 1959, Desdevises du Dezert, "Notes sur l'Inquisition espagnole au dix-huitieme siecle», Revue Hispanique, París, 1899.

Para una visión de las relaciones entre España y Francia en la época: Cfr. M. Artola, "La difusión de la ideología revolucionaria en los orígenes del liberalismo español", Arbor, mayo-junio, T. XXXI, pp. $447-490,1955$. A. Mousset, Un Témoin ignoré de la Revolution. Le Compte de Fernán-Nuñez ambassadeur d'Espagne a París (1781-1791), París, 1929, pp. 15 y ss. J. Chaumie, "La correspondance des agents diplomatiques de l'Espagne en France pendant la Revolution", Boulletin Hispanique, 1935, pp. 189-195; 352-367 y 502-536. Ch. A. Geoffroy de Grandmaison, L'Ambasade-française en espagne pendant la Revolution (1789-1801), París, Plon, 1892. A. Sorel, «La diplomatie française et l'Espagne de 1792 a 1797», Revue Historique, T. X-XIV. J. Pérez de Gızmán y Gallo, Las relaciones políticas de España con las demás potencias cle Europa al caer el conde de Floridablanca en 1972, Madrid, $1906 \mathrm{v}$ "La Embajada de España en París en los comienzos de la Revolución Francesa», España Moderna. T. CCXXVIII y CCXXIX, Madrid, 1907. 
seria: «no pasa día en que las dos salas (del Tribunal revolucionario) no envien a la guillotina 4 ó 5 mil infelices todos con el pretexto de ser enemigos de la libertad», leemos en una crónica del Mercurio.

A partir de septiembre de 1794, las «Noticias de Francia» reflejan aún timidamente, el nuevo espíritu que pronto inspirará las relaciones entre España y Francia, un proyecto de acercamiento consolidado a lo largo de 1795.

La firma de la paz de Basilea el 22 de julio de aquel año, representa un momento decisivo en las relaciones internacionales españolas que culmina con la firma del tratado de San Ildefonso en 1796. Los nuevos aires que inspiran la política exterior fuerzan al Mercurio hacia una propuesta informativa que busca una orientación diferente de la cpinión pública; un intento de aproximación a la causa francesa frente al rechazo del pasado. Después de Termidor, el cronista del periódico oficial desarrolla un análisis de los acontecimientos de Francia, distendido y, en ocasiones benévolo. Antes del 27 de julio, la condena, después, y por primera vez desde el comienzo de la Revolución, el periódico oficial hablaba de proyectos políticos importantes, de una nueva reorganización administrativa y de nuevos e interesantes planes sociales y económicos.

Cuando en septiembre de 1794 el cronista aludía al dia 27 "como uno de los más memorables que ha habido después del establecimiento de la Convención", reflejaba en realidad una incuestionable fidelidad a las nuevas directrices marcadas desde el poder. El plan que incluia una estrategia distinta en las relaciones con Francia parecia claramente definido a partir del verano de 1794. Una nueva política exterior que reclamaba el apoyo de una opinión pública favorable y que representaba un verdadero reto informativo para el Mercurio.

\section{Las «Noticias de Francia» antes del 27 de julio de 1794}

Antes de Termidor, el Mercurio incluía en sus largas y apretadas crónicas unas «Noticias de Francia» dedicadas a presentar la situación del país vecino; noticias abundantes que expresaban una condena tajante de la Revolución y de los políticos revolucionarios: el cronista hablaba de «monstruoso sistema», calificaba de «déspotas de la Francia» a los gobernantes, y de "feroces antropófagos» a los representantes de la nación. La etapa del Terror - fase de máxima crispación del gobierno de la Convención -, resultaba especialmente propicia para el desarrollo de esta crítica feroz. Las cartas de los 
representantes de provincias informando sobre medidas «de pacificación» suscitaban el pánico en un pueblo acosado por la miseria: "Continuamente llegan a la Convención cartas.... en que no se leen más que horrores y sangre - leemos en la crónica de marzo -; pero por más dolorosas que sean a la humanidad estas atroces relaciones, conviene repetirlas para que la edad presente y las venideras conozcan los funestos efectos de la anarquías.

El Mercurio dedicó especial atención a temas como la represión, la lucha por el poder entre los distintos partidos, la ineficacia política, la guerra dentro y fuera del país y la manipulación informativa del Gobierno sobre cuestiones de interés militar.

El cronista oficial no sólo condena la política del Terror sino que además se detiene en describir alguna de sus grandes aberraciones, «divisiones, conspiraciones, turbulencias, y otras causas de derramar sangre humana» y se escandaliza sobre todo por la crueldad de los jacobinos las declaraciones de Barrére sobre «la necesidad del terror» y de Carrier sobre «el terror saludable». En los primeros meses de 1794 el Mercurio insistía en los «suplicios, atrocidades, y, ejecuciones sin fin» en Tolón, París, Nantes, Estrasburgo etc., de los que eran responsables la Junta de Salud Pública y la Convención como cómplices de la represión.

La lucha a muerte entre las distintas facciones del Gobierno actuaba como un caldo de cultivo en el que eran posibles todos los rumores - maniobras contrarrevolucionarias reales o ficticias, conspiraciones, delaciones y calumnias - que acentuaban la imagem de una Francia caótica y ruinosa.

A partir de marzo, el Mercurio informa del cambio que se está produciendo en la opinión pública francesa sobre Robespierre:

«Robespierre empieza a temer la suerte que él ha hecho experimentar a tantos de sus compañeros: en la Junta de los Jacobinos tuvo que hacer su apología defendiéndose de la acusación que le hacían de tener toda la autoridad de un dictador" (10).

La ineficacia del Gobierno, consecuencia inevitable de la enconada lucha por el poder de sus miembros, alimentaba un estado de opinión contrario a la política de las Juntas: la de Salud Pública, «verdadero soberano de la Francia - leemos en el Mercurio -, continúa en mantener la ilusión y el fanatismo

(10) Mercurio histórico y político, «Noticias de Francia», marzo, 1794, pp. $227-228$. 
de aquella infeliz Nación con los medios acostumbrados de la seducción, del terror y del trastorno de todos los principios» ${ }^{11}$ ). La Junta de Instrucción era acusada por su «lentitud exasperante», la de Hacienda por su incapacidad para contener el crecimiento de los asignados que en 1794 habían alcanzado una cifra superior a los 6.000 millones de libras. La Convención por su parte, preocupada por los problemas militares más que por los asuntos políticos, recibía acusaciones constantes de inoperancia.

Las medidas sociales, políticas y económicas del Gobierno eran «escasas y demagógicas» según el Mercurio. En el campo económico y financiero, los bienes del clero, de la nobleza, de los condenados a muerte y de los «asentistas generales del antiguo gobierno», aunque como bienes nacionales servían de hipoteca a los asignados, resultaban aún insuficientes. Sin embargo, el problema más grave para Francia era sin duda el que planteaba la crisis de subsistencias, porque como decía el Mercurio: «si con el papel se puede suplir por algún tiempo la falta de numerario, la de las subsistencias no admite ningún suplemento" $\left({ }^{12}\right)$. Escaseaba el grano, y faltaba el pan y la carne, hasta el punto de que Barrére había llegado a proponer una "quaresma republicana», y en algunas zonas del país empezaba a hablarse de mendicidad, hambre y epidemias. En mayo, el Mercurio informaba sobre tumultos y motines, lamentándose «del triste espectáculo que ofrece la Francia, y principalmente la capital»: «.... las panaderías y carnicerías se ven cercadas todos los días por inmensas tropas del pueblo, que se disputan tumultuosamente una triste y escasa porción para subsistir» $\left({ }^{13}\right)$. La decepción cundía en un pueblo que había empeñado su vida en defender la Revolución junto al terror, el hambre y la miseria frente al abusivo enriquecimiento de los políticos.

La manipulación informativa - apoyada celosamente por los miembros del Gobierno y por los representantes de las Juntas - es otro de los temas a los que presta especial atención €.l periódico; una política informativa sesgada, sobre todo en relación con los temas militares: el silencio sobre los fracasos $\mathrm{y}$ el triunfalismo al referirse a las propias victorias; el cronista español se queja «del descaro con que se fingen las relaciones de los sucesos de la guerra en la Convención tanto interna como exterior». La guerra de la Vendée, la «buena causa» a la que se sumaban cada día sacerdotes, jóvenes, mujeres y

(11) Mercurio..., "Noticias», enero, 1794, p. 11.

(12) Mercurio..., "Noticias», marzo, 1794, p. 230.

(13) Mercurio..., «Noticias», mayo, 1794, p. 13. 
niños, era objeto de noticias breves y tendenciosas: la frase "ya no existe la Vendée», había sido muchas veces repetida y otras tantas desmentida por los hechos. Los informes de jefes y oficiales del ejército realista hablaban de victorias, de toma de ciudades y de deserción en las filas republicanas, mientras las sesiones de la Convención «se empleaban por la mayor parte en oir las ponderadas relaciones de Barrére sobre las victorias de los ejércitos franceses por todas partes». El Gobierno insistía en una superioridad militar inexistente: «pretendidas victorias, como decía el Mercurio, cuidando mucho de ocultar las repetidas e inmensas pérdidas en el Norte». Falsas noticias junto a una férrea censura a la que aludía nuestro cronista: «Se han dado providencias muy severas, y se acusa de traidores y contrarrevolucionarios a todos los que esparcen algunas de las muchas noticias funestas, que continuamente escriben del exercito del Norte» $\left({ }^{14}\right)$.

Mientras tanto, como recorda el cronista en el interior crecía el descontento a pesar de la represión:

«Estas frecuentes insurrecciones de los pueblos, sin escarmentar en el rigor con el que los tratan después de sojuzgados - comentaba el Mercurio -, prueba el extremo de desesperación a que los conduce la violencia y la tiranía de la Convención, pues prefieren la desolación a la voluntaria adhesión» (15).

En primavera, la lucha por el poder provoca nuevos enfrentamientos entre jacobinos y sectores moderados con un triste balance de traición y muerte:

"...tal es la historia de la revolución francesa, en que
vemos hacer un papel brillante al principio a Lafayette,
Mirabeau, Bailly, etc. - leemos en las «Noticias» de mayo -
los quales son condenados por Petión, Brissot y sus parcia-
les: a estos acusan y destruyen un Hebert, Chaumet, Chabot,
Danton \&. y estos últimamente perecen en la guillotina
por las intrigas del partido de Robespierre y sus sequaces,
a los quales sin duda espera un fin semejante» (16).

Las palabras del cronista iban a resultar muy pronto premonitorias.

(14) Mercurio..., «Noticias», junio, 1794, p. 159.

(15) Mercurio..., "Noticias», marzo, 1794, pp. 232-233.

(16) Mercurio..., «Noticias», mayo, 1794, pp. 11-12. 


\section{4. $E l$ «Mercuria histórico y político» y la reacción termidoriana}

Los acontecimientos que se producen en Francia a finales de julio de 1794, fueron precedidos de una intensa campaña antijacobina inspirada por el partido moderado; en círculos políticos y en algunos panfletos se hablaba del inminente peligro de deslizamiento de los jacobinos hacia posturas dictatoriales inspiradas por Robespierre y esos rumores encontraron acogida favorable en un pueblo acosado por la miseria y profundamente defraudado en sus expectativas revolucionarias. El Mercurio dedica varias crónicas a describir unos acontecimientos que considera decisivos para moderar el proceso de la revolución y que permiten plantear una nueva política de distensión en las relaciones entre España y Francia: «.... el día 25 y los dos siguientes se habló mucho en los Jacobinos y en la Convención de la opresión en que estaba la Nación, de ciertas pretensiones a la Dictadura, y de las escenas sangrientas que se preparaban». El 26 Robespierre, segun las «Noticias» pronunciaba un largo discurso en el que explicaba sus objetivos justificando las medidas adoptadas pero ni el fervor revolucionario ni la pasión consiguieron calmar la exasperación de sus enemigos. Los cargos contra el tirano eran muchos y graves: se le acusaba de «haver hecho prender a los mejores patriotas, y de formar todos los días la lista de proscripción de los que habían de ser degollados al día siguiente» $\left({ }^{17}\right)$. Los gritos de «toda la Convención y de las tribunas» provocaron un enorme alboroto, un movimiento desesperado contra Robespierre y sus colaboradores: Saint Just, Couthon, Lebas etc. Frente a él, la Convención, junto a él el comandante y los jefes de la Guardia Nacional, la Municipalidad, el Maire de París, casi todos los jacobinos y «una gran porción del pueblo». Los intentos de sublevar al pueblo fracasaron; Robespierre y los suyos fueron encarcelados y el 28 guillotinados.

La Revolución iniciaba una nueva etapa; caía uno de los personajes más importantes del momento, mostrando en aquel trance, según la versión del Mercurio, «la mayor timidez y abatimiento». La reacción Termidoriana, a pesar de alguna resistencia popular, conseguía imponerse:

"....empezaron a acudir Diputaciones de los barrios a la ciudad, de los discípulos de la escuela de Marte y de otros cuerpos, felicitando a la Convención por el feliz suceso contra los traidores, y haciendo protestas de su sumisión a la Convención, y de su horror a Robespierre».

(17) Mercurio..., «Noticias», septiembre, 1794, pp. 12-13. 
El cronista del Mercurio mostraba sua alegría por la caída del «déspota más cruel de aquel infeliz Reyno». Ahora las acusaciones contra el dictador se volvíam también contra la Convención que le había apoyado a pesar de sus protestas «de vivir dominada por el tirano». La campaña contra la obra y la figura de Robespierre desarrollada por la Convención insistía ahora en el «abatimiento y cprobio baxo el qual han gemido sus miembros».

Muerto Robespierre se iniciaba un sistema «de más moderación que el anterior»; se dictaron medidas contra las detenciones arbitrarias, se restablecieron las pensiones prometidas a. los eclesiásticos que juraron la Constitución y fueron liberados numerosos presos injustamente encarcelados. El Mercurio insiste una y otra vez sobre la gran transcendencia del cambio: «Se ha mudado enteramente de tono en París, y todas las ideas relativas a un sistema de moderación que antes se tenían por el mayor delito, se proponen ahora con toda confianza, y son aceptadas con el mayor aplauso» ${ }^{(18)}$.

Entre las medidas inmediatas destaca el restablecimiento de la libertad de Imprenta «reprimida» a pesar de estar reconocida en la Constitución y la reorganización de Juntas y Tribunales, aunque junto a los nuevos proyectos persistan viejas rivalidades como apunta el cronista:

«Aunque la Convención se ha mostrado casi unánime al adoptar estas disposiciones, los alborotos y discordias que se observan en casi todas sus secciones manifiestan que los ánimos están muy distantes de reunirse en un mismo sistema» (19).

La tendencia moderada parecía encontrar serios obstáculos entre los extremistas, los robespierrotes como se les llamaba, mientras la revisión de los decretos de la etapa anterior, responsables de «haber esparcido el temor por toda la Francia», y de haber «aniquilado la libertad se presentaba como una ardua tarea. El proceso contra la Junta revolucionaria de Nantes y contra el representante de la Convención en aquella ciudad, Carrier, se inscriben en esta ofensiva desesperada del partido moderado contra los jacobinos.

En diciembre, el Mercurio, por primera vez desde 1789, hablaba de justicia refiriéndose a la nueva política legislativa de Francia:

(18) Mercurio..., «Noticias», octubre, 1794, pp. 153-154.

(19) Mcrcilrio..., "Noticias», octubre, 1794, p. 156. 


\section{Revista de História das Ideias}

"La justicia que guía al presente a la Convención en todos estos Decretos, es generalmente aplaudida, pero los papeles públicos no hablan de ella sin echar algunas miradas sobre lo pasado, y sin quejarse de la paciencia demasiado larga con que los Representantes de la Nación han dexado el curso libre a tantos horrores; la Convención procura remediarlos en lo posible....» $\left({ }^{20}\right)$.

El periódico español hacía causa común con los moderados frente a los rigurosos o robespierrotes, escasos en número pero enormemente violentos, apoyando la beligerancia jacobina que exigía medidas de máxima dureza expuestas en una larga y acalorada sesión, en la que las cuatro Juntas reunidas elaboraron la exposición de motivos de una propuesta que pedía la suspensión de las reuniones de Jacobinos

"que en vez de servir de apoyo a la autoridad pública, querían dominarla, o más bien apropiársela: que no reconocían ningún poder legítimo, y haciéndose superiores a las leyes, querían precipitar por medio del desorden de la confusión. y usurpación del poder nacional, a una ruina inevitable al pueblo.... (21).

La Convención aprobó el Informe de las Juntas; las reuniones Jacobinas fueron suspendidas y sus centros clausurados. Parecía consolidarse el proyecto iniciado el 27 de julio a pesar del escepticismo de muchos: «Hemos sido engañados tantas veces sobre el verdadero patriotismo - decía un folletista anónimo - , que el pueblo debe tomar el prudente partido del observador imparcial en estos sangrientos debates» $\left({ }^{22}\right)$.

\section{Después de Termidor}

Tras la reacción termidoriana la Convención inicia una nueva etapa en la que aspira a consolidar un orden político firme, moderado y eficaz en el marco de la Revolución.

La lectura de las «Noticias de Francia» en el periodo que se extiende desde el otoño de 1794 hasta diciembre de 1795, $r \in f l e j a$ la nueva política del Gobierno francés que incluye varios importantes objetivos:

a) Reorganización política

b) Liberalización económica

(20) Mercurio..., «Noticias», diciembre, 1794, p. 456.

(21) Mercurio..., "Noticias», enero, 1794, p. 16.

(22) Mercurio..., «Noticias», noviembre, 1794, pp. 312-322. 


\section{El Mercurio Historico y Politico}

c) Pacificación nacional e internacional

e) Reforma institucional

El Informe del diputado Gregoire sobre el estado de Francia tras los sucesos de Termidor leído en la Asamblea, describía la dramática situación del país pasada ya la etapa del Terror: caos en la Industria, las Ciencias, las Artes y las Letras; iglesias abandonadas, edificios artísticos incendiados y bibliotecas despojadas como la de San Germán de los Prados. El Informe proponía como primera medida, la presentación de un "plan de instrucción» y de una política de reformas profundas en todos los campos de la vida pública, única forma de «organizar un gobierno republicano» como decía su autor.

La reorganización de la vida política se inicia, en efecto, a partir de una importante serie de medidas entre las cuales destaca por su especial interés el plan que afectaba a la Junta de Legislación que debía regular el nombramiento de cargos públicos puesto que la situación excepcional por la que atravesaba Francia había permitido prolongar una situación irregular en la que los derechos ciudadanos quedaban marginados:

«La Convención, con mantener el Gobierno revolucionario - leemos en la crónica de febrero-, ha conservado la facultad de nombrar para todos los empleos públicos en toda la extensión de la Francia, el qual nombramiento pertenece al pueblo según la constitución» (23).

El Plan señalaba con precisión las competencias concretas de las Juntas en aquellos nombramientos.

La elaboración de un proyecto de Código Civil, de medidas sobre sanidad y asistencia social entre otras, se inscriben en aquel proceso renovador.

La lucha entre jacobinos y moderados había anulado las iniciativas del Gobierno impidiendo llevar a buen puerto cualquier proyecto político. Después de Termidor, y a pesar de la gravedad de los enfrentamientos de abril y mayn, los miembros de la Convención querían emplearse, como decía el Mercurio, «en algunos objetos de utilidad pública».

La existencia de una economía de guerra en el marco de la Revolución, reclamaba un cambio de orientación en la nueva etapa iniciada el 27 de julio como única via para superar «la suma decadencia en que se hallan las Artes, el Comercio y la Agricultura». El proyecto de liberalización de una economía dirigida, sometida a fuertes medidas de control, incluía algunas

(23) Mercurio..., «Noticias», febrero, 1795, p. 144. 
importantes leyes como la supresión de la tasa - una ley «ruinosa» en opinión de muchos - que ahora permitiría la libertad de precios y la libre competencia, y la prohibición de lanzar nuevas emisiones de asignados manteniendo el crédito de los que estaban en circulación. Las medidas que fomentaban la inversión, el desarrollo de la agricultura, el comercio y la industria, apoyaban el retorno inmediato de un importante grupo de artesanos exiliados, de una burguesía atemorizada que había huido, perdiendo sus industrias, su maquinaria, sus materias primas y también sus mercados; los «artífices desanimados, como decía un diputado, han llevado a paises extrangeros sus talentos útiles, y sus manufacturas se han enriquecido con la pérdida de las nuestras». Libertad y promoción eran las únicas alternativas válidas para solucionar los problemas económicos del país: nuevas leyes sobre aduanas, prestamos, comunicaciones y sobre el retorno de artesanos exiliados, junto a una inflexible política contra la corrupción.

Conseguir la paz dentro y fuera de Francia constituye otro de los grandes objetivos del Gobierno en esta nueva etapa. Los triunfos del ejército francés frente a los aliados, impulsaron un sentimiento pacificador en el que coincidían los militares, el pueblo y el gobierno. Después de la conquista de Holanda se inicia un proceso de normalización de las relaciones internacionales francesas y en 1795 , casi un año después, se firmaban acuerdos parciales entre Francia, Holanda, Prusia y España.

Aunque el cronista del Mercurio mostraba interés por los problemas internos de Francia, apoyaba especialmente los objetivos pacificadores propuestos por Cambaceres ante la Convención: «....la protección de las operaciones militares de invierno, la tranquilidad interior, que depende de la total extinción de los jacobinos, y en fin la posibilidad de hacer la paz con algunas de las potencias beligerantes» $\left({ }^{24}\right)$. Como medida previa a las conversaciones de paz, era preciso desmontar una campaña de desprestigio contra Francia que insistía en el proselitismo revolucionario acusando a la Convención de intentar «democratizar» Europa; los franceses, a principios de 1795, olvidado el fervor expansionista girondino, únicamente aspiraban a la paz. En la sesión de la Convención del 30 de enero, Boissy de Anglas, en nombre de la Junta de Salud Pública, formulaba un deseo unánimemente compartido:

«....después de haber establecido por límites de la Francia, por una parte el océano, por otra los montes que le ciñen

(24) Mercurio..., «Noticias», febrero, 1795, p. 150. 


\section{El Mercurio Historico y Politico}

por el lado de España y de Italia, y finalmente los grandes rios que han conquistado las tropas francesas. convido a la Convención a declarar con la franqueza y dignidad propias de una República, las condiciones baxo las quales concederá la paz a sus enemigos» $\left({ }^{25}\right)$.

Francia quería pues la paz, y la querían también los paises aliados, pero se trataba de una paz planteada desde posiciones muy distintas: mientras la República francesa aspiraba a imponer sus condiciones - «....una paz asegurada por nuestra propia fuerza, como decía el diputado Merlín de Douay el 4 de diciembre, y por la impotencia en que quedarían nuestros enemigos de poder hacernos jamás ningún daño»-los paises aliados desconfíaban, y el Mercurio llamaba la atención sobre los graves peligros de la propuesta y sobre la inestabilidad de la política francesa. Los enfrentamientos y la lucha por el poder iban a desencadenar motines callejeros provocando una verdadera insurrección popular-germinal y prairial -, al grito de pan y Constitución de $1793\left({ }^{26}\right)$. Sobre el mismo peligro en había insistido Clauzel en la tribuna de la Convención al referirse a la necesidad de terminar con el enfrentamiento entre moderados y jacobinos: «¿Cómo quereis - decía -, que las Potencias beligerantes se atrevan a pediros la paz, ó la alianza, mientras consentís en vuestro seno a los jefes del partido que despedaza a la República?. ¿Quién podrá asegurar a estas Potencias el cumplimiento de vuestras promesas?»(27). El Gobierno francés proponía la paz «como el término no sólo de todas las calamidades inseparables del estado de guerra, sino también como el fin de todas estas agitaciones y trastornos domésticos, que acompañan siempre al estado de revolución», como decía cl mismo Clauzel. Los paises beligerantes por su parte, rechazaban las condiciones humillantes y sobre todo, las contrapartidas que afectaran a su integridad territorial.

El 16 de mayo de 1795 se firmaba la paz entre Francia y Holanda, el 29 de julio se notificaba a la Convención que la paz entre España y Francia había sido «ajustada»; el Mercurio en la crónica de septiembre, refleja la alegría de los diputados, «por las grandes ventajas que acarreaba esta paz para la pacificación general» y «por su gran importancia»: «.... levantándose con festivas aclamaciones (la Convención) ratificó el tratado, que ha llenado de júbilo a toda la Francia», un júbilo compartido por «todos los buenos ciudadanos franceses».

(25) Mercurio..., "Noticias», abril, 1795, p. 347.

(26) Cfr. Albert Soboul, Compendio de la Historia de la Revolución Francesa, Madrid, Tecnos, 1979, pp. 328-336.

(27) Mercurio..., «Noticias», febrero, 1795, p. 156. 


\section{Revista de História das Ideias}

La reforma constitucional representaba otro de los grandes objetivos de los termidoranos. La Constitución democrática de 1793 no había entrado nunca en vigor y ahora, la nueva etapa exigía la elaboración de un texto diferente «hasta el punto de ocupar toda la atención de los diputados» como decía el Mercurio. El proyecto, redactado por una Junta de once miembros, reconocía los derechos del hombre y del ciudadano, establecía una Cámara baja o Consejo de los Quinientos y un Consejo de Ancianos o Cámara alta y además un Directorio formado por cinco miembros que asumía el poder ejecutivo. Tras largas discusiones y con alguna modificación el texto fue aprobado y en general «aplaudido», "pués se esperaba que por este medio se pondría fin a los desórdenes». El Mercurio hablaba del espíritu de unión y amor al bién público de los diputados franceses destacando algunos comentarics importantes de políticos y diputados: «....todos los franceses tienen un mismo espíritu y un mismo corazón: el exercicio de los derechos legítimos de los unos no suministrará a los otros el pretexto de exagerar la medida de los suyos», decía el Orador de la sección de París. El diputado Delville, por su parte, creía que al fin, con la proclamación de la nueva Constitución, comenzaba una larga etapa de paz: «Ya se acabó para siempre la revolución - declaraba ante la Convención -, hacedlo ver a toda la Europa....».

Cuando el 31 de octubre se producía la elección del Directorio, el Gobierno de la Convención consideraba cumplidos algunos de sus más importantes objetivos políticos y militares. Empezaba una nueva etapa calificada por muchos historiadores como una "dictadura ineficaz», que iba a terminar con otra acción de fuerza: el golpe de Estado de Brumario. 